\title{
Commentary: Perfection is the enemy of good: Pushing the boundaries of donor heart criteria
}

\author{
Francis D. Pagani, MD, PhD
}

From the Department of Cardiac Surgery, University of Michigan, Ann Arbor, Mich.

Disclosures: Author has nothing to disclose with regard to commercial support.

Received for publication July 30, 2018; accepted for publication July 30, 2018; available ahead of print Sept 7, 2018

Address for reprints: Francis D. Pagani, MD, PhD, Department of Cardiac Surgery, 5161 Cardiovascular Center,

University of Michigan, 1500 East Medical Center Drive, Ann Arbor, MI 48109 (E-mail: fpagani@umich.edu).

J Thorac Cardiovasc Surg 2019;157:1880

$0022-5223 / \$ 36.00$

Copyright (c) 2018 by The American Association for Thoracic Surgery

https://doi.org/10.1016/j.jtcvs.2018.07.094

Despite significant advances in medical and mechanical circulatory support device therapies, heart transplantation remains the gold standard therapy for treatment of end-stage heart disease with median survival now exceeding 11 years. ${ }^{1}$ However, heart transplantation has been chronically plagued by donor shortages that have limited the epidemiologic benefit of this therapy. Even with recent increases in the number of heart transplant procedures performed in the United States (3244 heart transplants performed in 2017), ${ }^{2}$ substantially more patients could benefit from heart transplantation each year. The chronic shortage of donor heart organs is further exacerbated by application of inconsistent donor criteria and marked variability in donor acceptance rates among heart transplant centers with only 1 in 3 available donor hearts accepted for transplantation. ${ }^{3}$ Prior clinical studies assessing donor heart criteria have demonstrated that previously held notions of what constitutes acceptable donor heart criteria may be too restrictive and limits acceptance of suitable donor heart organs. ${ }^{4}$

In this issue of the Journal, Sibona and colleagues ${ }^{5}$ examine the impact of donor heart left ventricular function on long-term heart transplant outcomes using the United Network for Organ Sharing (UNOS) database. These investigators observed that donor heart dysfunction, assessed by left ventricular ejection fraction (LVEF), had no statistically significant impact on heart transplant mortality during 15 years of follow-up. Donor hearts with reduced LVEF were more commonly used in young male recipients and more commonly placed in recipients supported with mechanical ventilation. Follow-up evaluation of donor heart function at approximately 1 year demonstrated a normal LVEF for all groups, suggesting significant recovery of donor hearts with reduced LVEF.

There are a number of important caveats in the observations by Sibona and colleagues. First, the number of donor hearts with markedly reduced LVEF (ie, <40\%) represented only a very small fraction of the total number of heart transplants. Thus, the extrapolation of the study

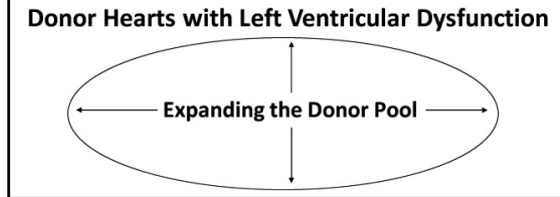

Expansion of the donor heart pool using donor hearts with left ventricular dysfunction.

\section{Central Message}

The use of donor heart organs with left ventricular dysfunction does not affect long-term heart transplant outcomes and may expand the donor heart pool.

See Article page 1865 .

findings to this group is limited to some degree by the small numbers that could fail to identify small, but clinically relevant and significant differences in survival. An important methodological limitation of the study, attributed to the inherent nature of large datasets, is that only $1 \mathrm{LVEF}$ was recorded in the UNOS dataset. Intuitively, one would think that the LVEF recorded in the UNOS dataset represented the first LVEF measurement at the time of the original offer. Thus, it is plausible that donor hearts with reduced LVEF underwent a period of resuscitation and evaluation with serial echocardiograms that demonstrated improvement in LVEF before donor organ acceptance and transplant.

Despite these limitations in the study design, the findings by Sibona and colleagues ${ }^{5}$ are important observations that should be carefully applied to our clinical practice. These data once again demonstrate that our perceived notion of what constitutes acceptable donor criteria may no longer be valid assumptions.

\section{References}

1. Lund LH, Edwards LB, Kucheryavaya AY, Dipchand AI, Benden C, Christie JD, et al. The registry of the international Society for Heart and Lung Transplantation: thirtieth official adult heart transplant report-2013; focus theme: age. J Heart Lung Transplant. 2013;32:951-64.

2. Transplant Trends. Available at: https://unos.org/data/transplant-trends/\#transplants_ by_organ_type+year+2017. Accessed July 30, 2018.

3. Khush KK, Zaroff JG, Nguyen J, Menza R, Goldstein BA. National decline in donor heart utilization with regional variability: 1995 - 2010. Am J Transplant. 2015;15:642-9.

4. Khush KK. Donor selection in the modern era. Ann Cardiothorac Surg. 2018;7: 126-34.

5. Sibona A, Khush KK, Oyoyo UE, Martens TP, Hasaniya NW, Razzouk AJ, et al. Long-term transplant outcomes of donor hearts with left ventricular dysfunction. J Thorac Cardiovasc Surg. 2019;157:1865-75. 